\title{
Increasing the Production of Volatile Fatty Acids from Corn Stover Using Bioaugmentation of a Mixed Rumen Culture with Homoacetogenic Bacteria
}

\author{
Nanditha Murali ${ }^{1,2}$, Keerthi Srinivas ${ }^{1,2}$ and Birgitte K. Ahring 1,2,3,*(D) \\ 1 Department of Chemical Engineering, Voiland College of Engineering and Architecture, Washington State \\ University, Pullman, WA 99163, USA; nanditha.murali@wsu.edu (N.M.); keerthivasan1@gmail.com (K.S.) \\ 2 Bio-Products, Sciences and Engineering Laboratory, Washington State University, Richland, WA 99354, USA \\ 3 Department of Biological Systems Engineering, Washington State University, Pullman, WA 99163, USA \\ * Correspondence: bka@wsu.edu; Tel.: +1-509-372-7682
}

check for

updates

Citation: Murali, N.; Srinivas, K.;

Ahring, B.K. Increasing the

Production of Volatile Fatty Acids

from Corn Stover Using

Bioaugmentation of a Mixed Rumen

Culture with Homoacetogenic

Bacteria. Microorganisms 2021, 9, 337.

https://doi.org/10.3390/

microorganisms 9020337

Academic Editor: Tim J. Dumonceaux

Received: 2 January 2021

Accepted: 4 February 2021

Published: 8 February 2021

Publisher's Note: MDPI stays neutral with regard to jurisdictional claims in published maps and institutional affiliations.

Copyright: (c) 2021 by the authors. Licensee MDPI, Basel, Switzerland. This article is an open access article distributed under the terms and conditions of the Creative Commons Attribution (CC BY) license (https:// creativecommons.org/licenses/by/ $4.0 /)$.
Abstract: Volatile fatty acids (VFA) are industrially versatile chemicals and have a major market. Although currently produced from petrochemicals, chemical industries are moving towards more biobased VFA produced from abundant, cheap and renewable sources such as lignocellulosic biomass. In this study, we examined the effect of bioaugmentation with homoacetogenic bacteria for increasing VFA production in lignocellulose fermentation process. The central hypothesis of this study was that inhibition of methanogenesis in an in vitro rumen bioreactor fed with lignocellulosic biomass hydrolysate increases the hydrogen partial pressure, which can be redirected towards increased VFA production, particularly acetic acid, through targeted bioaugmentation with known homoacetogenic bacteria. In this study, methanogenesis during ruminal fermentation of wet exploded corn stover was initially inhibited with $10 \mathrm{mM}$ of 2-bromoethanesulfonate (BES), followed by bioaugmentation with either Acetitomaculum ruminis and Acetobacterium woodii in two separate bioreactors. During the inhibition phase, we found that addition of BES decreased the acetic acid yield by $24 \%$, while increasing headspace hydrogen from $1 \%$ to $60 \%$. After bioaugmentation, the headspace hydrogen was consumed in both bioreactors and the concentration of acetic acids increased $45 \%$ when $A$. ruminis was added and $70 \%$ with $A$. woodii added. This paper demonstrates that mixed microbial fermentation can be manipulated to increase VFA production through bioaugmentation.

Keywords: acetic acid; Acetobacterium woodii; bioaugmentation; homoacetogens; rumen

\section{Introduction}

The chemical industry is slowly transitioning from using fossil fuels to using renewables biomass feedstocks to lower greenhouse gas emissions and their carbon footprint [1]. Although this seems like an obvious development, various obstacles must be overcome to achieve an efficient process for converting biomass to a high-value product [2]. One such obstacle is making the biomass susceptible to enzymatic hydrolysis. Lignocelluloses are naturally recalcitrant to enzymatic hydrolysis in lieu of the lignin sheath encompassing the cellulose and hemicellulose matrix [3]. Hence, pretreatment of biomass is the key to breaking down the lignin sheath efficiently. Although various pretreatment strategies including chemical pretreatment and hydrothermal pretreatment including steam explosion have been researched over the years, our laboratory has demonstrated the benefits of using the wet explosion (WEx) pretreatment [4,5]. WEx is done at an elevated temperature and pressure using only oxygen and water [6]. WEx was found to efficiently release cellulose and hemicellulose from lignocellulosic materials including straw and wood. Unlike conventional pretreatment methods, this method uses no harsh chemicals that can be detrimental to microbes during fermentation. Only low concentrations of inhibitory degradation products like furfural and hydroxymethylfurfural are produced during WEx, and the pretreated material is ready for further processing by enzymes and/or microbes [7]. 
Volatile fatty acids (VFA) are intermediates of anaerobic digestion produced during acidogenesis [8]. VFA are also the key fermentation product during ruminal fermentation, formed by conversion of organic feed materials by a mixed microbial consortia inhabiting the rumen. In contrast to the traditional sugar platform, where the pretreated material needs to be hydrolyzed by cellulolytic enzymes before fermentation to the desired product, the VFA platform can use pretreated biomass directly as raw material [9]. Besides, the VFA platform offers substrate flexibility, non-aseptic operations and mixed culture stability [10]. Microbes from the rumen can be used for biomass fermentation to VFA after methanogenesis has been inhibited or eliminated, a stage which has been defined as arrested anaerobic digestion [11]. The advantages of using a mixed microbial consortium such as a rumen culture during production of VFA compared to pure cultures is that there is no need for sterile conditions and no requirement for expensive enzymatic cocktails to produce sugars from pretreated biomass. However, low yields and high production costs hinder the commercial production of bio-based chemicals and fuels. Acetic acid, propionic acid, and butyric acid, in the molar ratio 6:2:1 [10], are the main products of rumen fermentation of cellulosic substrates. Studies have found that fermentation of alkali-treated corn stover under mesophilic conditions by a rumen culture, produced a VFA yield of $0.59-0.71 \mathrm{~g} / \mathrm{gVS}$ converted. The study also found that in addition to acetic, propionic, and butyric acids, small amounts of isobutyric and valeric acids were further produced [12].

The rumen primarily contains hydrogenotrophic methanogens, which use hydrogen as the electron donor to reduce carbon dioxide to methane [13]. Rumen bacteria are broadly classified into fermentative bacteria like Fibrobacter and Ruminococcus, acidogenic bacteria like Prevotella and Clostridium, acetogenic bacteria like Acetitomaculum and methanogenic Archaea like Methanobrevibacter and Methanosarcina [14,15]. Methanogens in the rumen work synergistically with other groups of microbes to keep the overall fermentation in balance, resulting in the production of methane and carbon dioxide besides VFA, which is adsorbed by the animal into the blood stream. It has been estimated that ruminal methanogenesis accounts for $10 \%$ energy loss in cattle [16]. Inhibition of methanogenesis in an artificial rumen bioreactor has been studied extensively, mainly to avoid energy loss in the animal [17]. These studies have indicated that an increase in $\mathrm{H}_{2}$ partial pressure is also, to a certain extent, inhibitory for the overall conversion in the rumen [18]. Mitigation strategies for methane has been studied using chemical inhibitors, methane analogs or ionophores. 2-Bromoethanesulfonic acid (BES), a coenzyme-M analog, will selectively inhibit methanogenesis and stimulate reductive acetogenesis [19]. In the same study, the addition of $0.03 \mathrm{M}$ BES and addition of Peptostreptococcus products yielded $2.14 \mathrm{mM}$ of acetic acid after $24 \mathrm{~h}$ of incubation with a mixture of hydrogen (80\%) and -carbon dioxide (20\%) in the headspace [19]. These studies showed no specifical inhibition of acetogenesis after BES addition to the mixed culture. However, inhibitors such as chloroform not only inhibit methanogenesis but also have an adverse effect on the $\mathrm{H}_{2}$-dependent acetogenesis [20].

It has been well established that reductive homoacetogenesis could be a beneficial substitution for methanogenesis, to reduce the significant energy loss to the ruminant [21]. Homoacetogens, including Moorella thermoacetica, a thermophilic bacteria utilizing hydrogen and carbon dioxide to autotrophically produce acetic acid, use the Wood Ljungdahl Pathway (WLP) to selectively produce acetic acid [22]. Herrero and Stuckey [23] defined bioaugmentation as "the process of adding selected strains/mixed cultures" to existing bioreactors for the improvement of fermentation efficiency. Although bioaugmentation has been studied for years in wastewater treatment and soil remediation [24], it has not been implemented successfully as it is considered less predictable than conventional bioremediation methods [23]. By the definition provided above, bioaugmentation depends on the ability of the added strain or mixed culture to work synergistically with the existing culture to perform the desired process change. Bioaugmentation of rumen fermentation with homoacetogens has been shown to be unsuccessful in the presence of living methanogens since they have a much higher affinity (10-100 times higher) for $\mathrm{H}_{2} / \mathrm{CO}_{2}$ when compared to the homoacetogens [25]. Bioaugmentation with homoacetogens for primarily increasing 
VFA production has not been previously studied. Most studies done in anaerobic digesters (AD) [26] have focused on adding specific cellulose-degradation bacteria to increase the biomethane yield $[27,28]$. Studies have shown that bioaugmentation of AD with thermophilic bacterial strains increased methane yield by $22-24 \%$ [29]. Other studies have shown similar trends, whereby bioaugmenting the first step of a two-step AD with the thermophilic Caldicellulosiruptor dictyoglomus led to a $93 \%$ increase in methane yield after 18 days of $\mathrm{AD}$ [28].

We hypothesized that VFA production (especially acetic acid) can be increased if methanogenesis is selectively inhibited in a rumen bioreactor, and the bioreactor is bioaugmented with $\mathrm{H}_{2}$-dependant homoacetogens. In the present study, we used pretreated (wet-exploded) corn stover as feedstock and a stable rumen culture grown on this substrate for three retention times. After inhibition of the methanogens by addition of BES, we further added homoacetogenic bacteria such as Acetobacterium woodii ATCC 29683 and Acetitomaculum ruminis ATCC 4738 to test the synergistic effect of the mixed microbial culture in the anaerobic digestion of lignocellulosic biomass on increasing VFA production.

\section{Materials and Methods}

\subsection{Inoculum}

Rumen fluid was collected and stored as described by Murali et al. [30]. The fresh rumen fluid was degassed under $80 \% \mathrm{~N}_{2}: 20 \% \mathrm{CO}_{2}$ (Oxarc ${ }^{\circledR}$ Inc., Pasco, WA, USA) for $30 \mathrm{~min}$, sealed and stored at $-20^{\circ} \mathrm{C}$ and $10 \%$ rumen fluid was added as inoculum to each of the bioreactors.

\subsection{Substrate}

Raw corn stover was obtained from Iowa State University and was processed as mentioned in our earlier study [30]. The milled corn stover was pretreated (wet exploded) as previously described by Biswas et al. [5]. The composition of the feed is shown in Table 1.

Table 1. Compositional data for pretreated (wet exploded) corn stover [30].

\begin{tabular}{lcccccc}
\hline & $\begin{array}{c}\text { Cellulose } \\
\mathbf{( w t} \mathbf{w})\end{array}$ & $\begin{array}{c}\text { Hemicellulose } \\
\mathbf{( w t} \%)\end{array}$ & Lignin $\mathbf{( w t )})$ & Ash (wt\%) & $\begin{array}{c}\text { Total Solids } \\
\mathbf{( w t} \%)\end{array}$ & $\begin{array}{c}\text { Volatile Solids } \\
\mathbf{( w t} \%)\end{array}$ \\
\hline Pretreated Corn Stover & 36.8 & 16.3 & 43.4 & 3.4 & 2.5 & 2.35 \\
\hline
\end{tabular}

\subsection{Bacterial Strains}

Two bacterial strains, Acetobacterium woodii ATCC 29683 and Acetitomaculum ruminis ATCC 47386 were purchased from American Type Culture Collection (ATCC; Manassas, VA, USA). Both mixed bacterial and pure culture inoculum were added to the fermenters at a concentration of $1 \times 10^{8}$ cells $/ \mathrm{mL}$.

\subsection{Fermentation}

\subsubsection{Control Fermenter}

One sterilized fermenter (3 L Applikon ${ }^{\circledR}$ ezControl autoclavable bioreactor (Applikon Biotechnology B.V, Schiedam, The Netherlands) was set up with pretreated corn stover at $2.5 \%$ TS. The fermenter was filled with $810 \mathrm{~mL}$ of substrate containing pretreated corn stover (2.5\% TS), corn steep liquor (2\%) (Sigma Aldrich, St. Louis, MO, USA) and $90 \mathrm{~mL}$ of inoculum. After stable performance for two retention times, $10 \mathrm{mM}$ of BES was added to the reactor to specifically inhibit the methanogenic population [31]. The fermenter was vigorously degassed under $\mathrm{N}_{2}-\mathrm{CO}_{2}(80: 20 w / w)$ for $45 \mathrm{~min}$ to remove any oxygen. Sodium hydroxide ( $5 \mathrm{~N}$ ) (Sigma Aldrich, MO, USA) was used initially to adjust the pH of the fermentation broth and to maintain the $\mathrm{pH}$ at 6.5 throughout the fermentation. The fermentation was done at $37^{\circ} \mathrm{C}$ with a stirrer speed of $200 \mathrm{rpm}$ and a hydraulic retention time (HRT) of 6 days. After addition of 2-bromoethanesulfonate (BES) (Sigma Aldrich, 
MO, USA), the fermentation was run for 5 HRTs (total 30 days) and operated in a semicontinuous mode, with an organic loading rate of $3.75 \mathrm{gTS} / \mathrm{L} /$ day. Liquid samples were collected every day for analysis.

\subsubsection{Bioaugmented Fermenters}

Two fermenters, one with $A$. woodii and another with A. ruminis were set up, similar to the control fermenter with feed added (as discussed in Section 2.4.1), and $45 \mathrm{~mL}$ of fresh rumen fluid and $45 \mathrm{~mL}$ of the respective bioaugmented strains were added. It should be noted that the BES addition in control and the bioaugmented fermenters were done at the same time of the microbial cycle, based on stabilized maximum methane production during ruminal fermentation of pretreated corn stover (data not shown). These fermenters were also operated semi-continuously, with an organic loading rate of $3.75 \mathrm{gTS} / \mathrm{L} /$ day and a hydraulic retention time of 6 days, for 5 HRTs (total of 30 days). Fermentation effluent samples were collected every day for analysis.

\subsection{Analyses}

\subsubsection{Measurement of VFA Using High Performance Liquid Chromatography}

The fermentation effluent $(2 \mathrm{~mL})$, from each of the fermenters, was centrifuged at 10,000 rpm for $10 \mathrm{~min}$ and the supernatant was analyzed using High Performance Liquid Chromatography (HPLC). The supernatant, from all fermenters, was diluted 6 times using $4 \mathrm{mM}$ sulfuric acid and filtered through a 0.2 micron PFTE filter for analysis. Analysis were done as described by Murali et al., [30] using an Aminex ${ }^{\circledR} 87 \mathrm{H}$ Column $250 \times 4.6 \mathrm{~mm}$ (BioRad, Hercules, CA, USA), and a Shodex RI-101 refractive index detector on the UltiMate ${ }^{\circledR}$ 3000 HPLC system (Dionex, Sunnyvale, CA, USA). Sulfuric acid (4 mM) in water was used as the eluent, flowing through the $87 \mathrm{H}$ column at a constant flow rate of $0.6 \mathrm{~mL} / \mathrm{min}$ in a constant temperature oven at $60^{\circ} \mathrm{C}$. The total analysis time of the fermentation sample was $68 \mathrm{~min}$.

\subsubsection{Gas Analyses Using Gas Analyzer}

Head space gas measurements were done daily using the Universal Mass Spectrometry Gas Analyzer, UGA-200 (Stanford Research Systems, Sunnyvale, CA, USA).

\subsubsection{Calculations}

Acetic, propionic, butyric and valeric acids were found to be the major acids produced during fermentation and were converted to acetic acid equivalents. The total VFA concentration is calculated in acetic acid equivalents using Equation (1) as follows:

Total VFA in acetic acid equivalents $=($ Acetic acid $)+\left(\right.$ Propionic Acid $\left.*\left(\frac{T O_{P A}}{T O_{A A}}\right) *\left(\frac{M W_{A A}}{M W_{P A}}\right)\right)$

$+\left(\right.$ Butyric Acid $\left.*\left(\frac{T O_{B A}}{T O_{A A}}\right) *\left(\frac{M W_{A A}}{M W_{B A}}\right)\right)+\left(\right.$ Valeric Acid $\left.*\left(\frac{T O_{V A}}{T O_{A A}}\right) *\left(\frac{M W_{A A}}{M W_{V A}}\right)\right)$

where $M W$ refers to the molecular weight of acetic acid $(A A)$, propionic acid $(P A)$, butyric/isobutyric acid $(B A)$ and valeric/isovaleric acid $(V A)$, which are the prominent $V F A$ produced during fermentation and $T O$ refers to the theoretical amount of oxygen required to completely breakdown each of these acids to carbon dioxide.

\subsection{Feedstock Characterization}

Feedstock characterization was done by analyzing the Total Solids (TS) and Volatile Solids (VS) and the biomass composition analysis of the feed and the effluent of each reactor. TS, VS and biomass composition analysis of the feed and effluent was done as described by Murali et al., [30].

\section{Results and Discussion}

\subsection{Effect of BES on Rumen Fermentation and VFA Production}

As indicated in Section 2.5, all the bioreactors showed stable performance for two retention times before any microbial manipulations were made and such stable performance 
has been previously shown [30]. Hence, in this study, day 0 is indicative of the bioreactor sample immediately after adding BES to the system and based on this assumption, the second addition of BES to the bioreactors was on day 15. This was consistently followed for both the control and the bioaugmented bioreactor. The VFA profile in the control bioreactor after BES addition is shown in Figure 1. As expected, it was found that after BES was added there was a drop in methane production to less than $5 \mathrm{wt} \%$ (not shown), and the hydrogen concentration in the headspace started to increase, reaching a maximum value of $60 \mathrm{wt} \%$ after 5 days (Figure 1a). Similar trends were observed in other studies, where inhibition of methanogens resulted in an increased hydrogen partial pressure $P_{\mathrm{H}_{2}} P_{\mathrm{H}_{2}}$ in the headspace [18]. Studies have shown that with complete inhibition of methanogenesis, $P_{\mathrm{H}_{2}}$ increased from $0.087 \mathrm{mM} /$ day to $1.83 \mathrm{mM}$ /day in continuous cultures [32]. It can be seen from Figure $1 \mathrm{~b}$ that acetic acid is the most prominent VFA produced, along with propionic and a low amount of butyric acid (very minute concentrations of valeric acid were produced and it was not consistent; hence, it is not shown in the graphs).
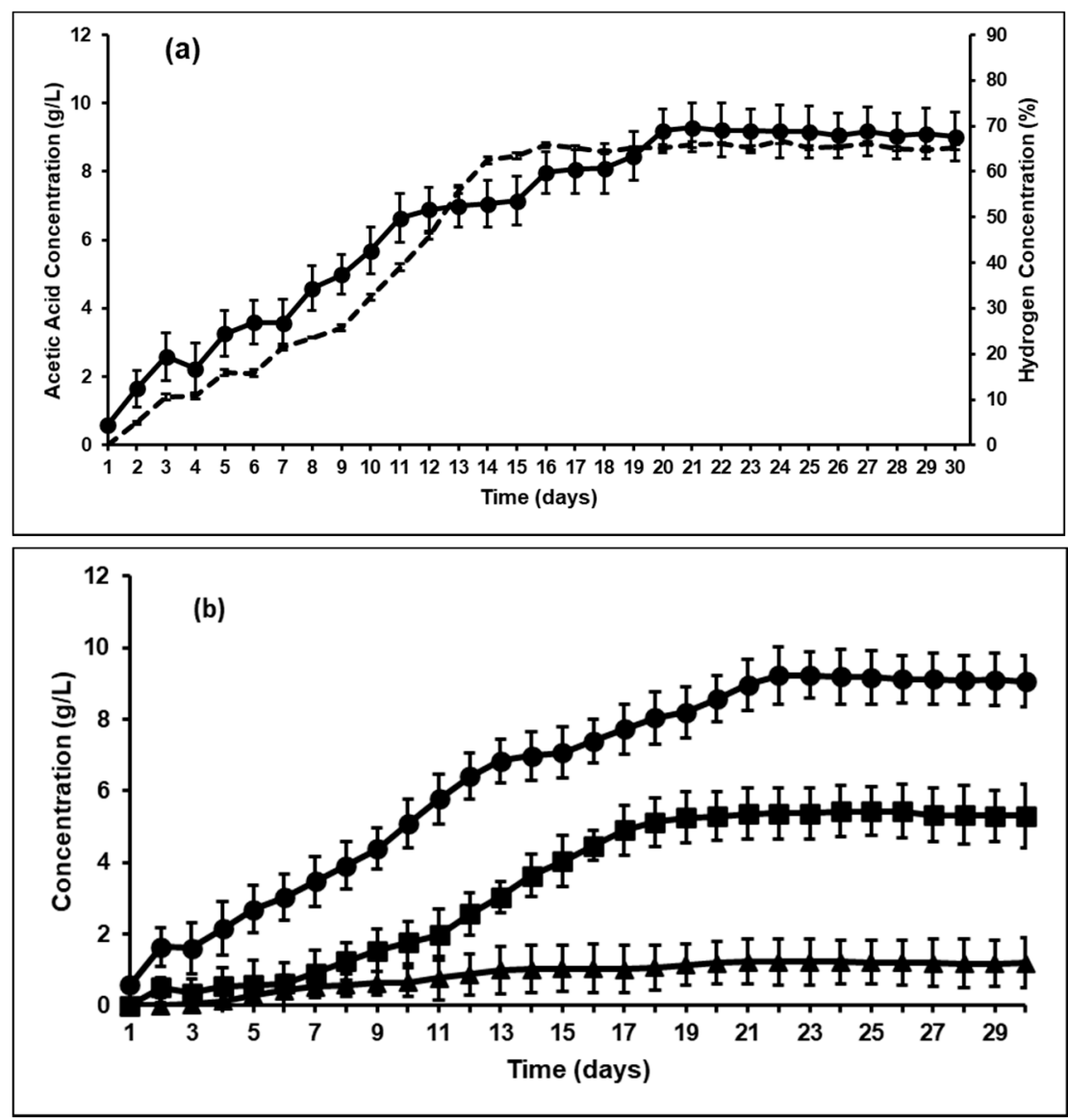

Figure 1. (a) Hydrogen concentration in headspace (wt\%) versus acetic acid concentration ( $\mathrm{g} / \mathrm{L}$ ); and (b) volatile fatty acids (VFA) profile; in control bioreactor after 2-bromoethanesulfonate (BES) addition and methanogenesis inhibition. (- Hydrogen concentration ( $w \mathrm{t} \%)$; Acetic acid concentration (g/L); - Propionic acid concentration (g/L); $\Delta$ Butyric acid concentration (g/L)).

While BES was not shown to have an adverse effect on specific homoacetogens, some studies have indicated that BES can inhibit certain non-methanogenic microbial populations too $[18,33]$. As seen from Table 2, BES addition decreased the overall VFA yield from ruminal fermentation of pretreated corn stover from $31.09 \mathrm{~g} / \mathrm{L}(1.25 \mathrm{~g} / \mathrm{gVS})$ to $21.41 \mathrm{~g} / \mathrm{L}(0.95 \mathrm{~g} / \mathrm{gVS})$. The acetic acid and total VFA productivity in the bioreactor without methanogens were $1.5 \mathrm{~g} / \mathrm{L} /$ day and $3.2 \mathrm{~g} / \mathrm{L} /$ day, respectively, and in the bioreactor with methanogenesis [30], the acetic acid and total VFA productivity was $2 \mathrm{~g} / \mathrm{L} /$ day and $5.4 \mathrm{~g} / \mathrm{L} /$ day, respectively. Individual VFAs also showed a similar trend (Table 2), 
where acetic, propionic, and butyric acids were reduced by $24 \%, 44 \%, 49 \%$, respectively, in reactors with BES addition compared to reactors without BES. Similar adverse effect of BES on VFA production during rumen fermentation was seen when using a pure cellulosic substrate such as Avicel [18]. Studies on rumen fermentation have shown that increased hydrogen production caused by methanogen inhibition using BES, would thermodynamically disfavor acetogenesis and instead flow $[\mathrm{H}]$ into other $[\mathrm{H}]$ sinks such as propionate, lactate, formate, succinate, etc. [34]. It can be seen from Table 2 that propionate production also dropped after BES addition and a similar effect was also found in other literature [35]. Another demonstrated effect is the adverse impact of high $P_{H_{2}}$ on the cellulose degradation, which eventually affected VFA production $[18,36]$.

Table 2. Volatile fatty acids concentrations $(\mathrm{g} / \mathrm{L})$ in bioreactors with and without bioaugmentation and with $10 \mathrm{mM}$ BES added. The bioreactors with and without methanogenesis were regarded as controls.

\begin{tabular}{ccccc}
\hline Bioreactor & $\begin{array}{c}\text { Acetic Acid } \\
(\mathbf{g} / \mathrm{L})\end{array}$ & $\begin{array}{c}\text { Propionic Acid } \\
(\mathbf{g} / \mathrm{L})\end{array}$ & $\begin{array}{c}\text { Butyric Acid } \\
(\mathbf{g} / \mathrm{L})\end{array}$ & $\begin{array}{c}\text { Total VFA in Acetic } \\
\text { Acid Equivalents }(\mathrm{g} / \mathrm{L})\end{array}$ \\
\hline Control; With Methanogenesis [30] & 12.26 & 10.08 & 2.42 & $31.09(1.25 \mathrm{~g} / \mathrm{gVS})$ \\
Control; (BES-added) Without Methanogensis & 9.29 & 5.63 & 1.23 & $21.41(0.95 \mathrm{~g} / \mathrm{gVS})$ \\
Bioaugmentation with A. ruminis after BES addition & 16.99 & 6.88 & 2.98 & $32.33(1.34 \mathrm{~g} / \mathrm{gVS})$ \\
Bioaugmentation with A. woodii after BES addition & 30.8 & 7.91 & 3.89 & $49.31(2.19 \mathrm{~g} / \mathrm{gVS})$ \\
\hline
\end{tabular}

\subsection{Effect of Bioaugmentation on Overall VFA Yield}

Based on the results discussed in Section 3.1, it was postulated that bioaugmentation of homoacetogens (A. woodii and A. ruminis) in fermenters that had a high hydrogen partial pressure $\left(P_{\mathrm{H}_{2}}\right)\left(P_{\mathrm{H}_{2}}\right)$ in the headspace would serve as an efficient alternate $[\mathrm{H}]$ sink, resulting in an increased acetic acid production. Previous studies have shown that such homoacetogens have shown significant growth and acetate production at such high hydrogen partial pressures with $\mathrm{CO}_{2}$ as the primary carbon substrate [19]. It can be seen from Figure 2 (and Table 2) that bioaugmentation with homoacetogens increased total VFA production $(32.33 \mathrm{~g} / \mathrm{L}(1.34 \mathrm{~g} / \mathrm{gVS})$ in the A. ruminis-augmented bioreactor and 49.31 ( $2.19 \mathrm{~g} / \mathrm{gVS}) \mathrm{g} / \mathrm{L}$ in the $A$. woodii-augmented fermenter) when compared to the non-augmented control bioreactor without methanogenesis ( $21.41 \mathrm{~g} / \mathrm{L}$ or $0.95 \mathrm{~g} / \mathrm{gVS}$ ). The most significant trend observed in Table 2 is that bioaugmentation with A. ruminis (which was primarily isolated from rumen sources) resulted in an almost similar total VFA yield as that of original rumen, further proving our hypothesis that a homoacetogen capable of growing under high $P_{\mathrm{H}_{2}}$ can serve as an efficient [H] sink, resulting in effective cellulosic degradation to VFA.

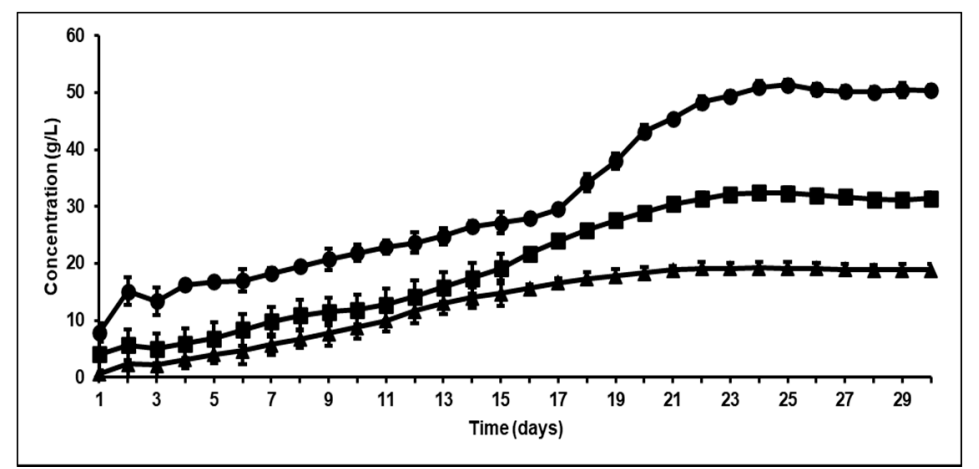

Figure 2. Comparison between total VFA concentration $(\mathrm{g} / \mathrm{L})$ as a function of time in control versus bioaugmented bioreactors ( $\boldsymbol{\Lambda}$ control bioreactor without methanogenesis; $\mathbf{\square}$ bioreactor augmented with $A$. ruminis; $\bullet$ bioreactor augmented with $A$. woodii). 
Previous studies have indicated that any changes to bioreactor performance after bioaugmentation are usually only operational for short periods of time [37]. This is primarily because of competition between the different microbial strains, and the fact that a system such as the rumen has developed over long periods of time and the resulting micro-flora is based on survival of the fittest. However, when methanogenesis is inhibited there is an opportunity for other strains to take up the space inhabited by these microbes, and as shown, this will lead to the increased production of more VFA, especially acetic acid. This effect is successfully shown in Figure 3, where the VFA productivity after bioaugmentation with $A$. ruminis or $A$. woodii was $6.2 \mathrm{~g} / \mathrm{L} /$ day and $10.4 \mathrm{~g} / \mathrm{L} /$ day, respectively, almost 2- to 3 -fold higher than in the control reactor without bioaugmentation.

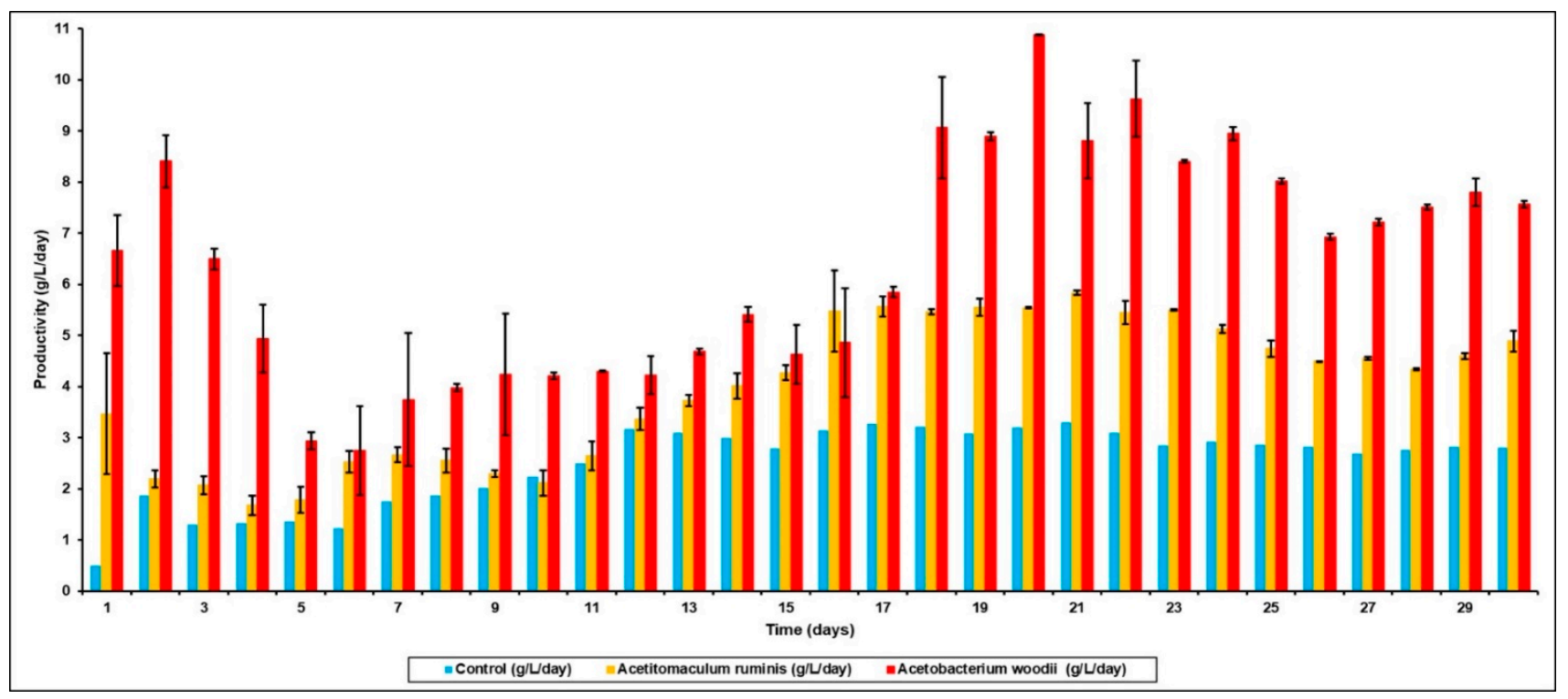

Figure 3. Total VFA productivity (g acetic acid equivalents/L/day) in control bioreactor after BES addition versus that bioaugmented with $A$. ruminis and $A$. woodii.

\subsection{Effect of Bioaugmentation on Individual VFA Yield}

The increase in VFA production, in particular, was in acetic $(45 \%)$, propionic $(18 \%)$ and butyric acids (59\%) in the $A$. ruminis-augmented bioreactor, when compared to the control bioreactor (after BES addition). However, in the bioreactor augmented with $A$. woodii, the percentage increase, when compared to control, was even higher-70\%, 29\% and 68\% of acetic, propionic and butyric acids, respectively.

The variations in the VFA concentrations as a function of time in the augmented bioreactors is shown in Figure 4. With A. ruminis (Figure 4a), the acetic acid concentration continually increased from day 1 to day 19, after which the acetic acid production stabilized at $16.9 \mathrm{~g} / \mathrm{L}(0.69 \mathrm{~g} / \mathrm{gVS})$ and similar trends were seen with propionic and butyric acid production. However, when bioaugmented with $A$. woodii, the acetic acid production was even higher, and the bioreactor reached stability on day 21 with $29.9 \mathrm{~g} / \mathrm{L}(1.29 \mathrm{~g} / \mathrm{gVS})$ of acetic acid (Figure $4 \mathrm{~b}$ ). It can also be seen from Figure 5 that the acetic acid productivity in $A$. ruminis and $A$. woodii augmented bioreactors was $3.9 \mathrm{~g} / \mathrm{L} /$ day and $6.3 \mathrm{~g} / \mathrm{L} / \mathrm{day}$, respectively. It can also be seen from Figure 5 that the acetate productivity trends mirrored that of the total VFA productivity, indicating that the production of other organic acids such as propionic and butyric acid did not significantly affect the total VFA production. This further confirms that increased acetate yield from bioaugmentation with homoacetogens specifically increased acetate production by serving as an efficient $[\mathrm{H}]$ sink (i.e., effectively replacing the methanogens). 

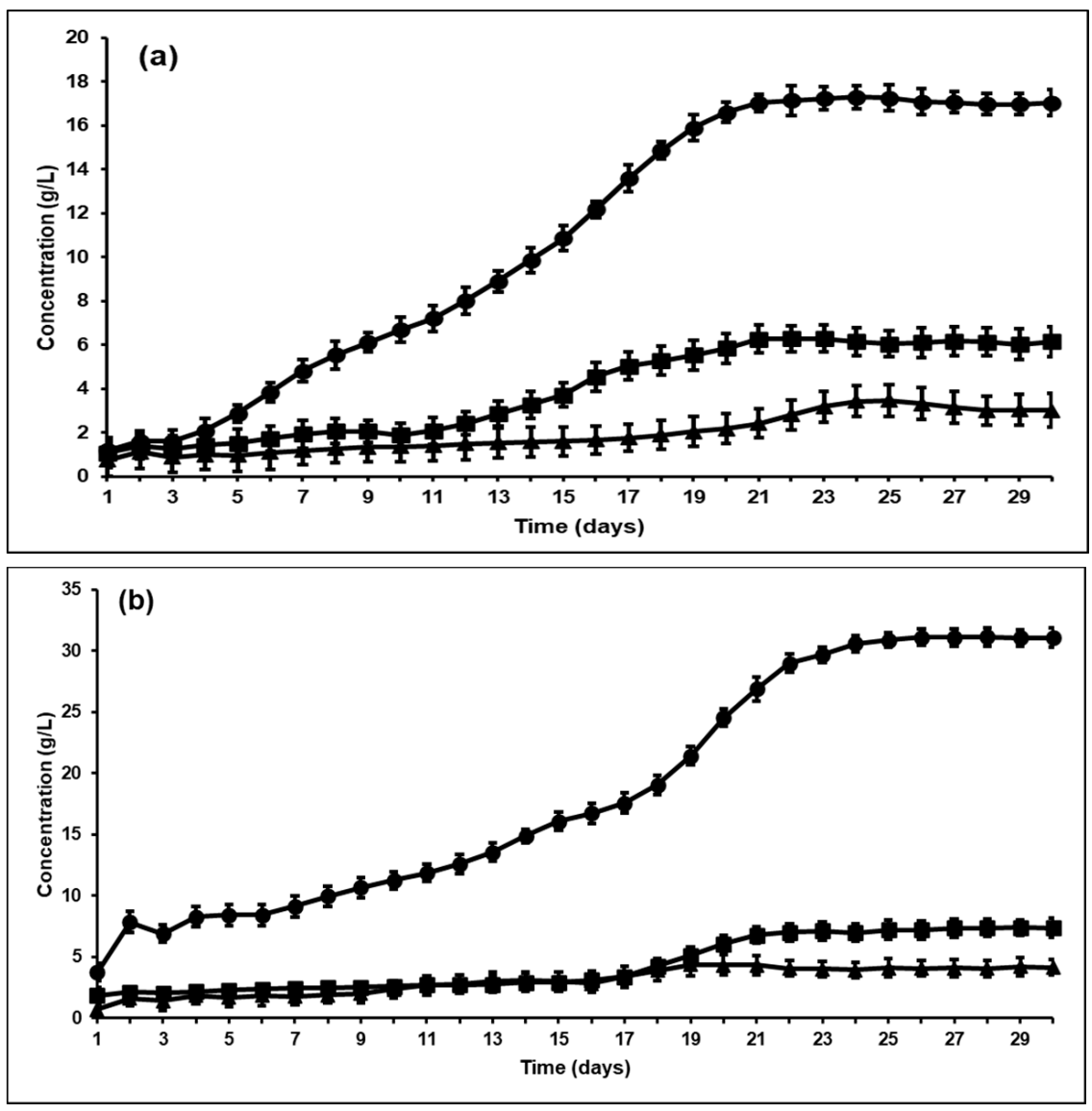

Figure 4. VFA (g/L) concentration as a function of time in bioreactors after BES addition and bioaugmentation with (a) Acetitomaculum ruminis and (b) Acetobacterium woodii (• Acetic acid concentration (g/L); Propionic acid concentration (g/L); $\mathbf{\Delta}$ Butyric acid concentration (g/L)).

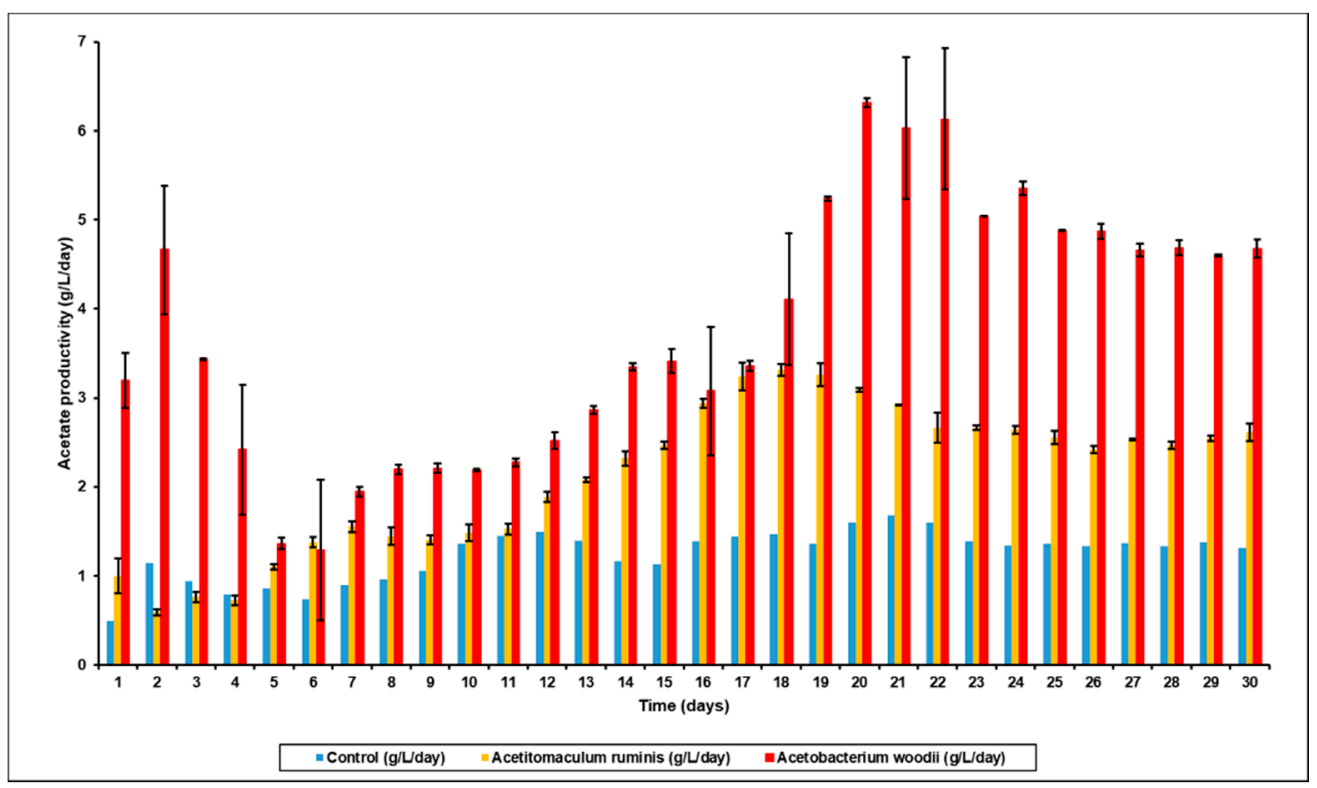

Figure 5. Acetate productivity (g/L/day) in control bioreactor after BES addition versus that bioaugmented with $A$. ruminis and A. woodii.

Other studies have found similar results, where bioaugmentation with $A$. woodii induced a homoacetogenic fermentation with heat activated sludge [38]. They found that 
from 1 mole of glucose, almost 1.19 mole of acetic acid was produced with $A$. woodii augmentation. Previous studies have reported similar results, that inhibition of methanogenesis possibly shifts ruminal fermentation towards homoacetogenesis, especially in the presence of $A$. ruminis [21]. Lopez et al. [39] also showed that inhibition of methanogenesis increases the hydrogen scavenging ability of hydrogenotrophic homoacetogenic bacteria like Eubacterium, Acetitomaculum and Acetobacterium, thereby increasing acetic acid yields by almost $51 \%$. The results from this study confirmed the hypothesis that reductive acetogenesis is indeed an alternative hydrogen sink to methanogenesis. However, while the bioaugmentation showed an increase in VFA production (especially acetic acid), the difference between the yields and productivities in $A$. ruminis and $A$. woodii augmented fermenters showed significant differences (Figures 3 and 5). As seen from Figure $1 \mathrm{~b}$, both $\mathrm{H}_{2}$ and acetic acid concentrations in the control bioreactor increased after BES addition. This trend was similar to previous studies that reported that, at high partial pressure of hydrogen, homoacetogenesis can be favored [40]. These studies also indicated that methanogenesis is favored at lower $\mathrm{H}_{2}$ partial pressures and hence, such a significant effect of bioaugmentation on VFA production using rumen may not have been achieved without first inhibiting the methanogenic population within the rumen. It can be seen from Figure $6 a, b$ that the $\mathrm{H}_{2}$ partial pressure in the fermenter headspace decreased upon bioaugmentation with both tested strains, $A$. ruminis and $A$. woodii. However, while the $\mathrm{H}_{2}$ concentration decreased to around $20 \mathrm{wt} \%$ and stayed constant as a function of time in the A. ruminis-augmented bioreactor, hydrogen was almost non-detectable in the $A$. woodii-augmented bioreactor after 9 days, indicating comparatively superior performance.
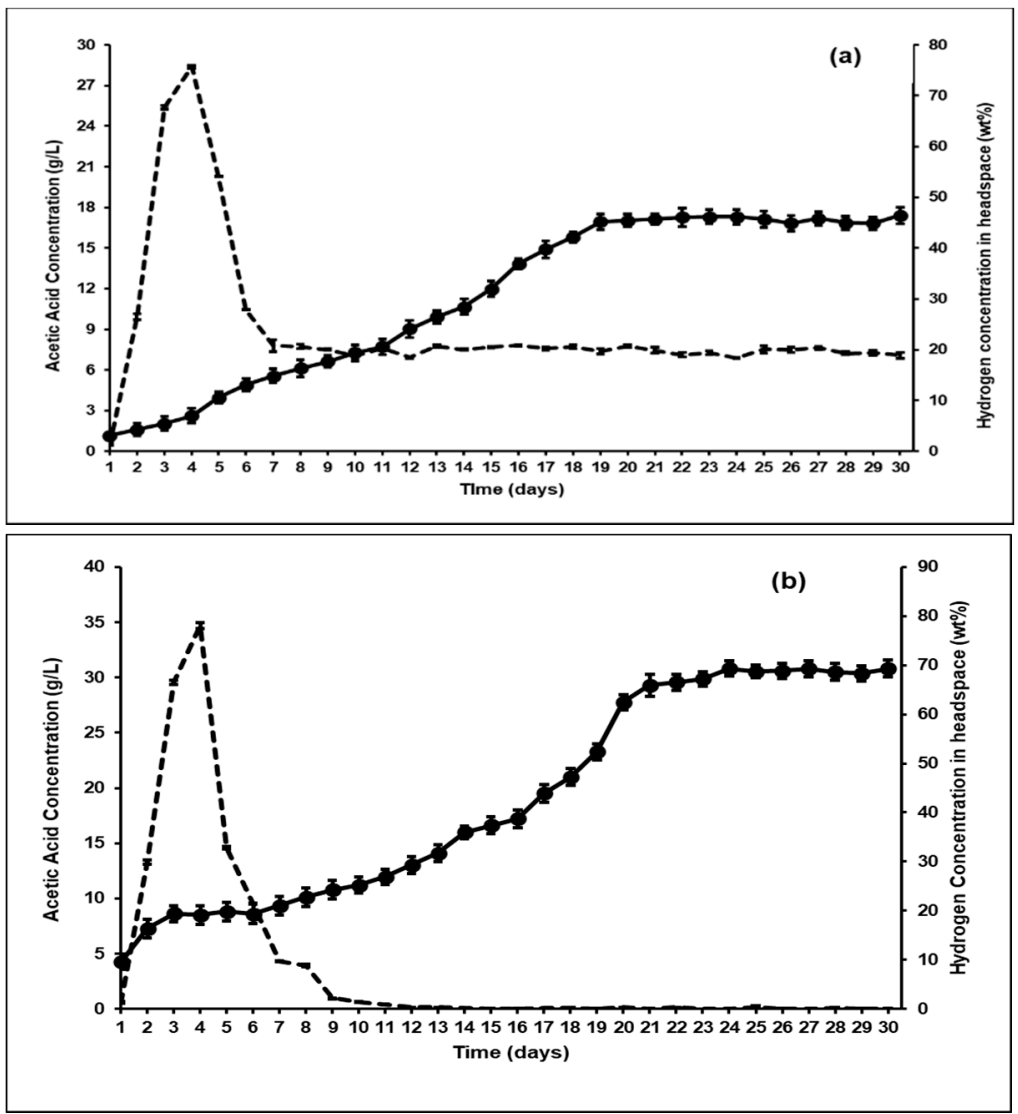

Figure 6. Hydrogen concentration in headspace $(w t \%)$ versus acetic acid concentration $(\mathrm{g} / \mathrm{L})$ in semicontinuous bioreactors bioaugmented with (a) Acetitomaculum ruminis and (b) Acetobacterium woodii (- Hydrogen concentration (wt \%); • Acetic acid concentration $(\mathrm{g} / \mathrm{L})$ ).

These differences indicate that $A$. woodii has a greater capability to completely consume the headspace hydrogen with $\mathrm{CO}_{2}$ to produce acetic acid through the Wood-Ljundahl 
pathway compared to A. ruminis. Some previous studies using A. woodii grown on $\mathrm{H}_{2} / \mathrm{CO}_{2}$ gaseous substrates have shown ascetic acid production of $20.37 \mathrm{~g} / \mathrm{L} /$ day, with the highest concentration found amongst hydrogenotrophic acetogens [41,42]. Another reason for the comparatively ineffective performance of $A$. ruminis-augmented reactor at $\mathrm{H}_{2}$ concentrations below $20 \%$ could be that the $\mathrm{H}_{2}$ concentration was below the threshold value that is usually required by $A$. ruminis for acetic acid production. This might explain the steady state concentration of hydrogen seen in the headspace of the fermenter bioaugmented with this strain (Figure 6a).

\subsection{Mass Balance Analysis and Feedstock/Effluent Characterization}

As discussed in Section 3.3, bioaugmentation resulted in higher VFA production (especially acetic acid) indicating that reductive homoacetogenesis will be active and utilize excess $\mathrm{H}_{2}$ in the bioreactor headspace after inhibition of methanogenesis. While the effective utilization of $\mathrm{H}_{2}$ in the headspace of the ruminal fermentation directly relates to an increase in VFA production, there is an added benefit of increased cellulolytic activity in the rumen. As previously discussed, studies using BES for inhibiting methanogenic activity have also shown a decrease in the cellulolytic activity of the ruminal bacteria with an increase in the $\mathrm{H}_{2}$ pressure [43]. This could also be attributed to the decreased VFA production in the control bioreactor. Table 3 shows the compositional analysis done at stable bioreactor conditions (day 30) to assess the carbohydrate degradation rate in the control fermenter in comparison to the bioaugmented bioreactors. It can be seen that the cellulose and hemicellulose concentrations in the bioaugmented bioreactors were significantly lower than that in the control bioreactor. The difference in cellulose and hemicellulose (total carbohydrate) consumption in the A. ruminis and A. woodii augmented reactors were found to be $18.3 \mathrm{wt} \%$ and $22.7 \mathrm{wt} \%$, respectively. We found no evidence of any lignin degradation, either with or without bioaugmentation. As previously found, there were no expectations on ligninolytic activity in the rumen at these conditions [30]. Assuming $1 \mathrm{~g}$ of carbohydrate could theoretically produce ca. $1 \mathrm{~g}$ of acetic acid, the carbohydrate consumption alone does not relate to the significant increase in acetic acid concentration in the effluent from $A$. woodii augmented fermenter. This difference in acetic acid concentrations between the two bioaugmented fermenters, however, could only be explained by the difference in carbohydrate consumption and increased consumption of the $\mathrm{H}_{2}$ in the $A$. woodii augmented fermenter (Table 3).

Table 3. Compositional analysis of wet exploded corn stover feed and effluent before and after bioaugmentation on day 30 of fermentation.

\begin{tabular}{ccccc}
\hline & Feed & Effluent A & Effluent B $^{\mathbf{3}}$ & Effluent C $^{\mathbf{4}}$ \\
\hline & \multicolumn{2}{c}{ Solid Fraction } \\
& * & & \\
\hline Total Carbohydrates (\%g/g biomass) & 53.1 & 44.4 & 34.8 & 30.4 \\
Cellulose (\%g/g biomass) & 36.8 & 31.9 & 25.9 & 23.6 \\
Hemicellulose (\%g/g biomass) & 16.3 & 12.5 & 8.9 & 6.8 \\
Soluble Lignin (\%g/g biomass) & 2.64 & 3.7 & 3.6 & 4.2 \\
Insoluble Lignin (\%g/g biomass) & 40.8 & 40.9 & 50.9 & 54.6 \\
Carbohydrate:Lignin Ratio & 1.22 & 0.99 & 0.64 & 0.52 \\
\hline & Liquid Fraction & & \\
\hline Acetic acid (g/L) & 0.34 & 9.29 & 16.99 & 30.8 \\
Propionic acid (g/L) & 0.17 & 5.63 & 6.88 & 7.91 \\
Butyric acid (g/L) & 0.11 & 1.23 & 2.98 & 3.89 \\
Hydrogen concentration (wt \%) & N/A & $65 \%$ & $4 \%$ & 0 \\
\hline
\end{tabular}

* Solid fraction was obtained after filtration and washing with water. ${ }^{1}$ Feed: Wet exploded corn stover $2.5 \%$ TS [30]. ${ }^{2}$ Effluent A: Effluent on Day 30 of fermentation without methanogens (Control) [30]. ${ }^{3}$ Effluent B: Effluent on Day 30 of fermentation bioaugmented with Acetitomaculum ruminis. ${ }^{4}$ Effluent C: Effluent on Day 30 of fermentation bioaugmented with Acetobacterium woodii. 


\section{Conclusions}

Inhibition of methanogenesis during ruminal fermentation has been well-studied, primarily, aimed at reducing methane emission from the cattle population. These studies have, however, shown that disruption of methanogenesis has a negative effect on the overall rumen fermentations and that the $\mathrm{H}_{2}$-scavenging function of the methanogens are important for a stable rumen function. In our study, we examined if homoacetogenes can substitute the role of methanogens during rumen fermentation and result in an increased production of VFA during fermentation of corn stover. The study is focused on two acetogenic strains, A. ruminis and $A$. woodii, which were both found to be capable of working in synergy with the ruminal consortia after BES addition, resulting in an increased VFA (particularly, acetic acid) production. The efficient utilization of the excess $\mathrm{H}_{2}$ accumulated after inhibition of methanogenesis was shown to increase the total VFA production to between $32.33 \mathrm{~g} / \mathrm{L}$ (1.34 g/gVS) and $49.31 \mathrm{~g} / \mathrm{L}(2.19 \mathrm{~g} / \mathrm{gVS})$ (acetic acid equivalents) compared to the control (i.e., non-augmented) bioreactor without methanogenesis $(21.41 \mathrm{~g} / \mathrm{L}$ or $0.95 \mathrm{~g} / \mathrm{gVS}$, acetic acid equivalents).

While bioaugmentation has been used previously, there has been no previous research studying the effect of bioaugmentation on improving VFA production. In another study conducted at our lab, we found that the efficient utilization of $\mathrm{H}_{2}$ in the bioaugmented reactors resulted in an increase in the cellulolytic activity during ruminal fermentation [18]. It was also found that an efficient $\mathrm{H}_{2}$-degrading acetogen, $A$. woodii, performed significantly better than $A$. ruminis, which seemed to be limited by a high $\mathrm{H}_{2}$ threshold concentration. The results from this current study not only increases our fundamental understanding of the effect of bioaugmentation in ruminal fermentation aimed at reducing methane activity, but also serves as an optimal alternative bioengineering tool capable of increasing the future biochemical production of organic acids.

Author Contributions: Conceptualization, N.M. and B.K.A.; methodology, N.M.; software, N.M.; investigation, N.M. and K.S.; data curation, K.S.; Writing-Original draft preparation, N.M.; WritingReview and editing, K.S. and B.K.A.; supervision, B.K.A. All authors have read and agreed to the published version of the manuscript.

Funding: This research received no external funding.

Institutional Review Board Statement: Not applicable.

Informed Consent Statement: Not applicable.

Data Availability Statement: Not Applicable.

Conflicts of Interest: The authors declare no conflict of interest.

\section{References}

1. Wan, C.X.; Li, Y.B. Microbial pretreatment of corn stover with Ceriporiopsis subvermispora for enzymatic hydrolysis and ethanol production. Bioresour. Technol. 2010, 101, 6398-6403. [CrossRef] [PubMed]

2. Wang, F.-Q.; Xie, H.; Chen, W.; Wang, E.-T.; Du, F.-G.; Song, A.-D. Biological pretreatment of corn stover with ligninolytic enzyme for high efficient enzymatic hydrolysis. Bioresour. Technol. 2013, 144, 572-578. [CrossRef] [PubMed]

3. Himmel, M.E.; Ding, S.Y.; Johnson, D.K.; Adney, W.S.; Nimlos, M.R.; Brady, J.W.; Foust, T.D. Biomass recalcitrance: Engineering plants and enzymes for biofuels production. Science 2007, 315, 804-807. [CrossRef]

4. Rana, D.; Rana, V.; Ahring, B.K. Producing high sugar concentrations from loblolly pine using wet explosion pretreatment. Bioresour. Technol. 2012, 121, 61-67. [CrossRef] [PubMed]

5. Biswas, R.; Uellendahl, H.; Ahring, B.K. Wet explosion pretreatment of sugarcane bagasse for enhanced enzymatic hydrolysis. Biomass Bioenergy 2014, 61, 104-113. [CrossRef]

6. Biswas, R.; Uellendahl, H.; Ahring, B.K. Wet explosion: A universal and efficient pretreatment process for lignocellulosic biorefineries. BioEnergy Res. 2015, 8, 1101-1106. [CrossRef]

7. Njoku, S.I.; Uellendahl, H.; Ahring, B.K. Comparing oxidation and dilute acid wet explosion pretreatment of Cocksfoot grass at high dry matter concentration for cellulosic ethanol production. Energy Sci. Eng. 2013, 1, 89-98. [CrossRef]

8. Sawatdeenarunat, C.; Sung, S.; Khanal, S.K. Enhanced volatile fatty acids production during anaerobic digestion of lignocellulosic biomass via micro-oxygenation. Bioresour. Technol. 2017, 237, 139-145. [CrossRef] 
9. Murali, N.; Srinivas, K.; Ahring, B.K. Biochemical production and separation of carboxylic acids for biochemical applications. Fermentation 2017, 3, 22. [CrossRef]

10. Weimer, P.J.; Nerdahl, M.; Brandl, D.J. Production of medium-chain volatile fatty acids by mixed ruminal microorganisms is enhanced to ethanol in co-culture with Clostridum Kluyveri. Bioresour. Technol. 2015, 175, 97-101. [CrossRef]

11. Weimer, P.J.; Russell, J.B.; Muck, R.E. Lessons from the cow: What the ruminant animal can teach us about consolidated bioprocessing of cellulosic biomass. Bioresour. Technol. 2009, 100, 5323-5331. [CrossRef] [PubMed]

12. Hu, Z.-H.; Yu, H.-Q. Application of rumen microorganisms for enhanced anaerobic fermentation of corn stover. Process Biochem. 2005, 40, 2371-2377. [CrossRef]

13. Graeme, A.; Christopher, M. Methanogen genomics to discover targets for methane mitigation technologies and options for alternative $\mathrm{H}_{2}$ utilization in the rumen. Aust. J. Exp. Agric. 2008, 48, 28-37.

14. Angelidaki, I.; Ellengaard, L.; Ahring, B.K. Applications of the anaerobic digestion process. In Biomethanation II; Ahring, B.K., Angelidaki, I., Dolfing, J., Ellengaard, L., Gavala, H.N., Haagensen, F., Mogensen, A.S., Eds.; Springer: New York, NY, USA, 2003; pp. $1-34$.

15. Ahring, B.K.; Biomethanation, I. Biomethanation I; Ahring, B.K., Ed.; Springer: New York, NY, USA, 2003 ; pp. 1-31.

16. Ungerfeld, E.M. Inhibition of rumen methanogenesis and ruminant productivity: A meta analysis. Front. Vet. Sci. 2018, 5, 1-13. [CrossRef] [PubMed]

17. Van Kessel, J.A.S.; Russell, J. The effect of pH on ruminal methanogenesis. FEMS Microbiol. Ecol. 1996, 20, 205-210. [CrossRef]

18. Ahring, B.K.; Murali, N.; Srinivas, K. Fermentation of cellulose with a mixed microbial rumen culture with and without methanogenesis. Ferment. Technol. 2018, 7, 152. [CrossRef]

19. Nollet, L.; Demeyer, D.; Verstraete, W. Effect of 2-Bromoethanesulfonic acid and Peptostreptococcus productus ATCC 35244 addition of stimulation of reductive acetogenesis in the ruminal ecosystem by selective inhibition of methanogenesis. Appl. Environ. Microbiol. 1997, 63, 194-200. [CrossRef]

20. Xu, K.; Liu, H.; Chen, J. Effect of classic methanogenic inhibitors on the quantity and diversity of archae community and the reductive homoacetogenic activity during the process of anaerobic sludge digestion. Bioresour. Technol. 2010, 101, 2600-2607. [CrossRef]

21. Gagen, E.J.; Denman, S.E.; McSweeney, C.S. Acetogenesis as an alternative to methanogenesis in the rumen. In Livestock Production and Climate; Mallik, P.K., Bhatta, R., Takahashi, J., Kohn, R., Prasad, C.S., Eds.; CAB International: Oxfordshire, UK, 2015; pp. 292-303.

22. Schiel-Bengelsdorf, B.; Durre, P. Pathway engineering and synthetic biology using acetogens. FEBS Lett. 2012, 586, 2191-2198. [CrossRef]

23. Herrero, M.; Stuckey, D.C. Bioaugmentation and its application in wastewater treatment: A review. Chemosphere 2015, 140, 119-128. [CrossRef]

24. Cycon, M.A.; Mrozik, A.; Piotrowska-Seget, Z. Bioaugmentation as a strategy for the remediation of pesticide-polluted soil: A review. Chemosphere 2017, 172, 52-71. [CrossRef]

25. Ren, N.Q.; Chua, H.; Chan, S.Y.; Tsang, Y.F.L.; Wang, Y.J.; Sin, N. Assessing optimal fermentation type for bio-hydrogen production in continuous-flow acidogenic reactors. Bioresour. Technol. 2007, 98, 1774-1780. [CrossRef]

26. Acs, N.; Bagi, Z.; Rakhely, G.; Minarovics, J.; Nagy, K.; Kovacs, K.L. Bioaugmentation of biogas production by a hydrogen producing bacterium. Bioresour. Technol. 2015, 186, 286-293. [CrossRef]

27. Nielsen, H.B.; Mlandenovska, Z.; Ahring, B.K. Bioaugmentation of a two stage thermophilic (68C/55C) anaerobic digestion concept for improvement of the methane yield from cattle manure. Biotechnol. Bioeng. 2007, 97, 1638-1643. [CrossRef] [PubMed]

28. Costa, J.C.; Barbosa, S.G.; Alves, M.M.; Sousa, D.Z. Thermo-chemical pre- and biological co-treatments to improve hydrolysis and methane production from poultry litter. Bioresour. Technol. 2013, 111, 141-147. [CrossRef] [PubMed]

29. Strang, O.; Acs, N.; Wirth, R.; Maroti, G.; Bagi, Z.; Rakhely, G.; Kovacs, K.L. Bioaugmentation of the thermophilic anaerobic biodegradation of cellulose and corn stover. Anaerobe 2017, 46, 104-113. [CrossRef]

30. Murali, S.; Fernandez, S.; Ahring, B.K. Fermentation of wet-exploded corn stover for the production of volatile fatty acids. Bioresour. Technol. 2017, 227, 197-204. [CrossRef]

31. Chidthaisong, A.; Conrad, R. Specificity of chloroform, 2-bromoethanesulfonate and fluoroacetate to inhibit methanogenesis and other anaerobic processes in anoxic rice field soil. Soil Biol. Biochem. 2000, 32, 977-988. [CrossRef]

32. Ungerfeld, E.M. Shifts in metabolic hydrogen sinks in the methanogenesis-inhibited ruminal fermentation: A meta-analysis. Bioresour. Technol. 2010, 101, 6398-6403. [CrossRef]

33. Nagaraja, T.G. Ionophores and antibiotics in ruminants. In Biotechnology in Animal Feeds and Animal Feeding; Wallace, R.J., Chesson, A., Eds.; VCH: Weinheim, Germany, 1995; pp. 171-204.

34. Ungerfeld, E.M. Metabolic hydrogen flows in rumen fermentation: Principles and possibilities of interventions. Front. Microbiol. 2020, 11, 589. [CrossRef] [PubMed]

35. Wang, M.; Ungerfeld, E.M.; Wang, R.; Zhou, C.S.; Basang, Z.Z.; Ao, S.M.; Tan, Z.L. Supersaturation of dissolved hydrogen and methane in rumen of Tibetian sheep. Front. Microbiol. 2016, 7, 850. [CrossRef]

36. Zhou, Z.; Meng, Q.; Yu, Z. Effect of methanogenic inhibitors on methane production and abundances of methanogens and cellulolytic bacteria in In Vitro ruminal cultures. Appl. Environ. Microbiol. 2011, 77, 2634-2639. [CrossRef] 
37. Yu, F.B.; Ali, S.W.; Guan, L.B.; Li, S.P.; Zhou, S. Bioaugmentation of a sequencing batch reactor with Pesudomonas putida ONBA-17 and its impact on reactor bacterial communities. J. Hazard. Mater. 2010, 176, 20-26. [CrossRef]

38. Yan, B.H.; Selvam, A.; Xu, S.Y.; Wong, J.W.C. A novel way to utilize hydrogen and carbon dioxide in acidogenic reactor through homoacetogenesis. Bioresour. Technol. 2014, 159, 249-257. [CrossRef] [PubMed]

39. Lopez, S.; Mcintosh, F.M.; Wallace, R.J.; Newbold, C.J. Effect of adding acetogenic bacteria on methane production by mixed rumen microorganisms. Anim. Feed Sci. Technol. 1999, 78, 1-9. [CrossRef]

40. Demirel, B.; Scherer, P. The roles of acetotrophicc and hydrogenotrophic methanogens during anaerobic conversion of biomass to methane: A review. Rev. Environ. Sci. Biotechnol. 2008, 7, 173-190. [CrossRef]

41. Groher, A.; Weuster-Botz, D. Comparative reaction engineering analysis of different acetogenic bacteria for gas fermentation. J. Biotechnol. 2016, 228, 82-94. [CrossRef] [PubMed]

42. Kantzow, C.; Mayer, A.L.; Weuster-Botz, D. Continuous gas fermentation by Acetobacterium woodii in a submerged membrane reactor with full cell retention. J. Biotechnol. 2015, 212, 11-18. [CrossRef] [PubMed]

43. Lamed, R.J.; Lobos, J.H.; Su, T.M. Effects of stirring and hydrogen on fermentation products of Clostridium thermocellum. Appl. Environ. Microbiol. 1988, 54, 1216-1221. [CrossRef] 